\title{
Resistance of fly ash-Portland cement blends to thermal shock
}

\section{Tatiana Pyatina}

Materials scientist, Sustainable Energy Technologies, Brookhaven National Laboratory, Upton, NY, USA
Toshifumi Sugama

Chemist, Sustainable Energy Technologies, Brookhaven National Laboratory, Upton, NY, USA

Thermal-shock resistance of high-content fly ash-Portland cement blends was tested in the following ways. Activated and non-activated blends with $\mathbf{8 0 - 9 0 \% ~ f l y ~ a s h ~ F ~ ( F A F ) ~ w e r e ~ l e f t ~ t o ~ s e t ~ a t ~ r o o m ~ t e m p e r a t u r e , ~ t h e n ~ h y d r a t e d ~ f o r ~} 24 \mathrm{~h}$ at $85^{\circ} \mathrm{C}$ and then for an additional $24 \mathrm{~h}$ at $300^{\circ} \mathrm{C}$, and tested in five thermal-shock cycles $\left(600^{\circ} \mathrm{C}\right.$ heat $-25^{\circ} \mathrm{C}$ water quenching). X-ray diffraction (XRD) and thermal gravimetric analyses, along with calorimetric measurements and scanning electron microscope-energy-dispersive X-ray tests demonstrated that the activated blends form more hydrates after $24 \mathrm{~h}$ at $300^{\circ} \mathrm{C}$, and achieve a higher short-term compressive strength than do non-activated ones. Sodium meta-silicate and soda-ash engendered the concomitant hydration of ordinary Portland cement (OPC) and class F fly ash (FAF), with the formation of mixed crystalline FAF-OPC hydrates and FAF hydrates, such as garranite, analcime and wairakite, along with the amorphous FAF hydration products. In sodium sulfate-activated and nonactivated blends separate OPC (tobermorite) and FAF (amorphous gel) hydrates with no mixed crystalline products formed. The compressive strength of all tested blends decreased by nearly $50 \%$ after five thermal-shock test cycles. These changes in the compressive strength were accompanied by a marked decrease in the intensities of XRD patterns of the crystalline hydrates after the thermal shock. There was no significant difference in the performance of the blends with different activators.

\section{Introduction}

One of the challenges in ensuring the integrity of geothermal wells is the stability of the cement sheath under conditions of thermal shock when wells, constructed under relatively mild temperatures of about 80 to $100^{\circ} \mathrm{C}$, are moved into production, and the temperature may rise by several hundred degrees. Differences in temperature between the injection- and production-heat-carrier fluids may further impose a constant thermal shock on the cement. In enhanced geothermal systems, the cement experiences an additional thermal stress during the stimulation process, when large volumes of cold water are injected through the hot wells to create a connected network of fractures to make the wells more economical. To withstand such stress, the cement must be resistant to thermal shock and thermal-cycle fatigue.

Previous work (Gill et al., 2012) focused on investigating the effectiveness of sodium metasilicate-activated fly ash, class $F$ (FAF, fly ash) in improving the thermal shock resistance of aluminium oxide $\left(\mathrm{Al}_{2} \mathrm{O}_{3}\right)$ rich refractory calcium aluminate cement (RCAC). RCAC consists of three crystalline phases, corundum $\left(\alpha-\mathrm{Al}_{2} \mathrm{O}_{3}\right)$, calcium monoaluminate $\left(\mathrm{CaO} \cdot \mathrm{Al}_{2} \mathrm{O}_{3}(\mathrm{CA})\right)$ and calcium dialuminate $\left(\mathrm{CaO} \cdot 2 \mathrm{Al}_{2} \mathrm{O}_{3}\left(\mathrm{CA}_{2}\right)\right)$. Accelerated thermal-shock-resistance tests, wherein cement cured for $24 \mathrm{~h}$ at $200^{\circ} \mathrm{C}$ under the pressure of $6.89 \mathrm{MPa}$ was sintered at $500^{\circ} \mathrm{C}$ for an additional $24 \mathrm{~h}$, and subsequently quenched in $25^{\circ} \mathrm{C}$ water, showed that this cement withstands five cycles of thermal shock without any failure in its integrity, such as visual cracks, partial surface spalling or disintegration. Further, this cement showed no significant change in compressive strength, maintaining a strength of more than 6.89 MPa. Analyses of its phase composition demonstrated that, after autoclaving at $200^{\circ} \mathrm{C}$, four crystalline products formed in the cement, boehmite and katoite from the RCAC, hydrogrossular by the interaction between RCAC and FAF, and hydroxysodalite from FAF. After thermal-shock testing, three crystalline phase-transformations occurred: (a) boehmite $\rightarrow \gamma-\mathrm{Al}_{2} \mathrm{O}_{3}$, (b) katoite $\rightarrow$ calcite and (c) hydroxysodalite $\rightarrow$ carbonated sodalite. Thus, these three phases, $\gamma-\mathrm{Al}_{2} \mathrm{O}_{3}$, calcite from RCAC and carbonated sodalite from FAF, maintained the integrity of the cementitious structure, and sustained the material's compressive strength developed after the autoclaving. RCAC improved the resistance of the FAF to the thermal shock.

Fly ash is a very attractive material for using in cement owing to its wide availability, good workability and compatibility with various cementitious materials. Replacing ordinary Portland cement (OPC) by fly ash also helps to abate carbon dioxide $\left(\mathrm{CO}_{2}\right)$ emissions during the production of the cement.

However, the reactivity of FAF at temperatures below $90^{\circ} \mathrm{C}$ generally is low so it is very difficult to assemble an ideal cementitious structure along with a desirable strength at the early curing ages (Berry et al., 1990; Feldman et al., 1990; 
Gurney et al., 2012; Lam et al., 2000). There are two ways to deal with this issue. One is to incorporate it into the cementitious reactants, such as OPC, PC clinker, gypsum or lime, which can form ettringite $\left(\mathrm{AFt}, \mathrm{Ca}_{6} \mathrm{Al}_{2}\left(\mathrm{SO}_{4}\right)_{3}(\mathrm{OH})_{12} \cdot 26 \mathrm{H}_{2} \mathrm{O}\right)$, monosulfate $\left(\mathrm{AFm}, \mathrm{Ca}_{4} \mathrm{Al}_{2} \mathrm{O}_{6}\left(\mathrm{SO}_{4}\right) \cdot 14 \mathrm{H}_{2} \mathrm{O}\right)$, calcium silicate hydrate $\left(\mathrm{CaO}-\mathrm{SiO}_{2}-\mathrm{H}_{2} \mathrm{O}\right)$ and portlandite $\left(\mathrm{Ca}(\mathrm{OH})_{2}\right)$, along with the alkaline activators, such as sodium silicate made with various sodium oxide $\left(\mathrm{Na}_{2} \mathrm{O}\right)$ /silicon dioxide $\left(\mathrm{SiO}_{2}\right)$ mole ratios, $\mathrm{NaOH}, \mathrm{KOH}, \mathrm{Ca}(\mathrm{OH})_{2}, \mathrm{Na}_{2} \mathrm{CO}_{3}, \mathrm{Na}_{2} \mathrm{SO}_{4}$ alone or in combination (Bentz and Ferraris, 2010; Donatello et al., 2013a, 2013b; Duran-Herrera et al., 2011; Pacewska and Wilinska, 2013; Shi and Day, 1995). The other way to increase FAF reactivity is to incorporate only alkaline activators without any additional cementitious reactants (Andini et al., 2008; Chi and Huang, 2013; Davidovits, 1991; FernandezJimenez and Palomo, 2005; Joshi and Kadu, 2012; Komnitsas and Zaharaki, 2007; Lohani et al., 2012; Mandal and Majumdar, 2009; Palomo et al., 1999; Rodriguez et al., 2013; van Jaarsveld et al., 2002).

In FAF blends with other cementitious materials, the FAF initially serves as a filler, densifying, and thus strengthening, the structure of faster reacting cementitious phases at the early curing stages. Subsequently, the dissolution of FAF by the alkaline activators, followed by pozzolanic reactions, causes the formation of a secondary binding phase, an amorphous $\mathrm{Na}_{2} \mathrm{O}$ - and $\mathrm{CaO}-\mathrm{Al}_{2} \mathrm{O}_{3}-\mathrm{SiO}_{2}-\mathrm{H}_{2} \mathrm{O}$ gel (Ben Haha et al., 2010; Berry et al., 1990; Deschner et al., 2012; Fraay et al., 1989). The early reaction of cementitious materials assures the early development of strength. In the RCAC/FAF system, RCAC plays that role. As for the OPC-FAF blends, the combined systems of OPC and FAF had better thermal stability (Donatello et al., 2014; Gill et al., 2012) and resistance to acid (Donatello et al., 2013b), compared with those of OPC alone.

In exploring the activation of alkaline fly ash, most of the work has been done with $100 \%$ FAF. Very high $\mathrm{OH}^{-}$concentrations in solutions of alkaline activators, such as sodium hydroxide $(\mathrm{NaOH})$ and/or sodium Na- or K-silicate, promote the dissolution of FAF. Thereafter, the interactions between dissociated ionic species, such as $\mathrm{Al}(\mathrm{OH})^{4-}, \mathrm{H}_{3} \mathrm{SiO}_{4}^{-}, \mathrm{Na}^{+}$, and $\mathrm{K}^{+}$, take place within the assemblage of hydroxylated sodium and potassium-aluminosilicate gel. Finally, dehydroxylationpolycondensation reactions between the hydroxylated aluminosilicates result in a three-dimensional amorphous aluminosilicare network (Davidovits, 1991; Komnitsas and Zaharaki, 2007) that contributes to the development of early strength, and offers an excellent resistance to acid (Bakharev, 2005) and to high temperatures (Bakharev, 2006; Bignozzi et al., 2014). FAF-rich alkali-activated cements appear to possess an adequate resistance to both the high heat followed by water quenching thermal shock, and high-temperature sintering environments.

For geothermal wells wherein the bottom-hole temperature may reach $300^{\circ} \mathrm{C}$ at pressures of $8.3 \mathrm{MPa}$, the resistance of
FAF-reach OPC blends with different activators cured at $300^{\circ} \mathrm{C}$ to thermal-shock cycles is of particular interest. This study focused on the resistance of 80/20- and 90/10-wt $\%$ FAF/OPC blends activated by three different sodium (Na)alkaline activators, namely, sodium silicate, sodium carbonate and sodium sulfate, to thermal-shock cycles. For comparison, non-activated FAF-rich OPC systems with the same masscomponent ratios also were studied. The work addressed the following four major subjects

(a) characterising the effect of these alkaline activators on the cements' setting behaviours by measuring the amount of heat released during blends' hydration

(b) identifying the crystalline and amorphous phases formed in $300^{\circ} \mathrm{C}$-autoclaved cements

(c) investigating the transformation of these phases after thermal-shock tests

(d) exploring the microstructure developed in autoclaved cements and its alteration after the thermal-shock tests.

This microstructural information is correlated with the changes in compressive strength after thermal-shock testing. To conduct accelerated tests a considerable thermal stress was imposed on cement. The multiple heat-water quenching cycle procedure was performed under an extremely large temperature difference between heating the cement at $600^{\circ} \mathrm{C}$ and water quenching it at $25^{\circ} \mathrm{C}$.

\section{Experimental procedures}

The effect of three sodium-alkaline activators, sodium metasilicate (SMS) anhydrous, soda ash (SA) or sodium carbonate anhydrous, and sodium sulfate (SS) anhydrous, on changes in cement's integrity during repeated thermal shock was evaluated. The 93\% SMS-beaded powder under the trade name 'MetsoBeads 2048,' was supplied by the PQ Corporation; it had a 50.5/46.6 sodium oxide/silicon dioxide weight ratio. The particle size of this beaded powder ranged from 0.23 to 0.85 $\mathrm{mm}$. The $99 \cdot 8 \%$ 'soda ash light' supplied by BRI-Chem Corp. had the following distribution of particle size in weight percent: $88 \%-0.15 \mathrm{~mm}, 8.4 \%-0.45 \mathrm{~mm}, 2.3 \%-0.075 \mathrm{~mm}$ and $1 \cdot 3 \%-0.6 \mathrm{~mm}$. Sodium sulfate of more than $99 \cdot 9 \%$ purity was obtained from Sigma-Aldrich. Boral Material Technologies, Inc. supplied FAF and White Cap Construction Supply Inc. provided type II OPC. Table 1 gives the chemical compositions of these cement-forming materials detected by energy-dispersive X-ray spectrometer (EDX), along with the composition of the sodium metasilicate activator. The X-ray powder diffraction (XRD) data showed three major crystalline phases in FAF: quartz $\left(\mathrm{SiO}_{2}\right)$, mullite $\left(3 \mathrm{Al}_{2} \mathrm{O}_{3} \cdot 2 \mathrm{SiO}_{2}\right)$ and haematite $\left(\mathrm{Fe}_{2} \mathrm{O}_{3}\right)$.

The cementitious blends had FAF/OPC weight ratios of $80 / 20$ and $90 / 10$. Activators were added at $6 \cdot 2 \%$ by the total weight of the blend to make the dry mixtures. The cement slurries were prepared by adding an appropriate amount of water to 


\begin{tabular}{|c|c|c|c|c|c|c|c|c|}
\hline Component & $\begin{array}{c}\mathrm{Al}_{2} \mathrm{O}_{3} \\
\text { (aluminium } \\
\text { oxide) }\end{array}$ & $\begin{array}{c}\mathrm{CaO} \\
\text { (calcium } \\
\text { oxide) }\end{array}$ & $\begin{array}{c}\mathrm{SiO}_{2} \\
\text { (silicon } \\
\text { dioxide) }\end{array}$ & $\begin{array}{c}\mathrm{Fe}_{2} \mathrm{O}_{3} \\
\text { (iron (III) } \\
\text { oxide) }\end{array}$ & $\begin{array}{c}\mathrm{Na}_{2} \mathrm{O} \\
\text { (sodium } \\
\text { oxide) }\end{array}$ & $\begin{array}{c}\mathrm{K}_{2} \mathrm{O} \\
\text { (potassium } \\
\text { oxide) }\end{array}$ & $\begin{array}{c}\mathrm{TiO}_{2} \\
\text { (titanium } \\
\text { dioxide) }\end{array}$ & $\begin{array}{c}\mathrm{SO}_{3} \\
\text { (sulfur } \\
\text { trioxide) }\end{array}$ \\
\hline OPC, Type II cement, atomic \% & $2 \cdot 9$ & 66 & 18 & $3 \cdot 8$ & $0 \cdot 34$ & $1 \cdot 3$ & - & $5 \cdot 4$ \\
\hline Fly ash class F, atomic \% & 35 & $2 \cdot 7$ & 50 & $7 \cdot 1$ & $0 \cdot 30$ & $3 \cdot 1$ & $1 \cdot 6$ & - \\
\hline Sodium meta silicate, wt. \% & - & - & $46 \cdot 6$ & - & $50 \cdot 5$ & - & - & - \\
\hline
\end{tabular}

Table 1. Oxide composition of ordinary Portland cement (OPC), fly ash F (FAF) and sodium meta-silicate (SMS) used in the study

these mixtures. The water/cement ratio ranged from 0.44 to $0 \cdot 45$. After thoroughly hand-mixing the cement slurries for $1 \mathrm{~min}$, samples were cast in cylindrical moulds $(20 \mathrm{~mm}$ dia. and $40 \mathrm{~mm}$ long), and left to harden for $24 \mathrm{~h}$ at room temperature. Then, the hardened cements were placed for $24 \mathrm{~h}$ into an oven at relative humidity $>95 \%$ and temperature of $85^{\circ} \mathrm{C}$. Next, they were autoclaved at $300^{\circ} \mathrm{C}$ under a pressure of 8.3 MPa for another $24 \mathrm{~h}$. To obtain information on their thermal-shock resistance, a multiple heating-water quenching cycle test was conducted: in one cycle, the $300^{\circ} \mathrm{C}$-autoclaved cements were placed in an air oven at $600^{\circ} \mathrm{C}$ for $24 \mathrm{~h}$, and then these heated cements were rapidly immersed in water at $25^{\circ} \mathrm{C}$. This $600^{\circ} \mathrm{C}$ heating $\rightarrow$ water quenching cycle was repeated five times.

After assessing the strength of the specimens, they were ground into a very fine powder and dried at $90^{\circ} \mathrm{C}$ for $24 \mathrm{~h}$ before thermogravimetric testing and X-ray diffractometric characterisation. The former analysis was done on approximately $10 \mathrm{mg}$ of a sample heated at a rate of $20^{\circ} \mathrm{C} / \mathrm{min}$ in nitrogen, using TGA-Q50 from TA Instruments. The samples were examined using a Philips XRG 300 X-ray diffractometer with a $40 \mathrm{kV}$, $40 \mathrm{~mA}$ copper anode X-ray tube. The results were analysed using the PDF-4/Minerals 2013 database of the International Center for Diffraction Data. The morphologies of the cements were explored on typical spots of freshly fractured samples with a Jeol $7600 \mathrm{~F}$ scanning electron microscope (SEM) equipped with an EDX Oxford Link microanalysis system. The specimens were placed on metallic holders and chromiumcoated. The hydration behaviour of the blends was studied using isothermal calorimetry at $25^{\circ} \mathrm{C}$. The slurries were mixed by hand, poured into ampoules and placed into the calorimeter to follow evolving heat for several days.

\section{Results and discussion}

Hydration behaviour of FAF/OPC blends with different activators at $25^{\circ} \mathrm{C}$ - calorimetric measurements

Figure 1 shows the calorimetric curves of hydration heat for 80/20 weight ratio FAF/OPC blends with and without activators at $25^{\circ} \mathrm{C}$. The beginning of the heat release in non-activated and SS-activated blends took longer ( $4 \mathrm{~h} 42 \mathrm{~min}$ and $3 \mathrm{~h}$ $18 \mathrm{~min}$, respectively) than in the blends with SMS- and



Figure 1. Normalised heat released at $25^{\circ} \mathrm{C}$ during hydration of $80 / 20$ weight ratio FAF/OPC blend activated with (a) SA, (b) SMS, (c) SS and (d) non-activated

SS-activators (immediate heat release for the SMS-activated one, and 50 min delay in the SA-activated one). Importantly, most of the heat was released with high intensity in a short time of about $8 \mathrm{~h}$ for the last two blends, whereas nonactivated and SS-activated blends released their heat in wide, strongly or partially overlapping peaks over several days. Although each heat peak likely corresponds to a combination of the events of wetting, dissolution, alkaline activation and hydrate formation, it is likely that in the non-activated blend, the OPC, which is more reactive, starts hydrating before the FAF, which is activated later by the OPC hydration products. As a result the initial OPC hydration and formation of the first hydrates takes place as would be expected for the OPC hydrating alone. Among the activated blends, only the one with the SS-activator had well-separated peaks of heat release, whereas, for the SMS- and SA-activated blends all exothermic reactions were clearly much more concurrent, resulting in merged peaks. The integrated heat release was the highest for the SS-activated blend $(37.5 \mathrm{~J} / \mathrm{g}$ of slurry). The non-activated, SMS- and SAactivated blends released similar amounts of heat $(32 \cdot 7,30 \cdot 4$ 
and $31.6 \mathrm{~J} / \mathrm{g}$ of slurry, respectively). It is likely that in the case of the SMS-activated blend, part of the heat was released before the instrument re-equilibrated after the ampoules' introduction and hence was not registered, resulting in underestimation of the actual total heat value.

In summary the results suggest that, without an activator, the blend hydrated in two somewhat separate stages with the cement hydrating first; but, in the presence of the activators, the hydration of cement and fly ash pozzolanic reactions occurred simultaneously.

\section{Compressive strength}

Table 2 shows the compressive strength of $300^{\circ} \mathrm{C}$-autoclaved non-activated, and SMS-, SA- and SS-activated 80/20 and 90/ 10 weight ratio FAF/OPC cements before and after thermalshock testing. For the non-activated cements, the 80/20 and 90/10 ratio samples before testing had compressive strength of 16.5 and 8.9 MPa, respectively. These values increased in activated cements and the increase was more dramatic for the blends with the higher FAF content (90/10 FAF/OPC), which could be explained by higher contribution of the activated FAF to the strength. For the $80 / 20$ FAF/OPC blends the compressive strength increase was $22 \%, 16 \%$ and $4 \%$, respectively, for the SS-, SMS- and SA-activators, while for the $90 / 10$ blends the respective increases in compressive strength were $55 \%, 38 \%$ and $34 \%$. Among the activators, SS conferred the highest compressive strength and SA the lowest.

Three samples of each non-activated and activated blend were tested in thermal-shock tests. Two out of three samples of the non-activated 80/20 OPC/FAF blend developed multiple cracks and disintegrated after the annealing in an oven at $600^{\circ} \mathrm{C}$. Consequently, the five-cycle thermal-shock tests and

\begin{tabular}{|c|c|c|c|}
\hline \multirow[b]{2}{*}{ Activator } & \multicolumn{2}{|c|}{ Compressive strength, $\mathrm{MPa}$} & \multirow{2}{*}{$\begin{array}{c}\text { \% Compressive } \\
\text { strength } \\
\text { decrease }\end{array}$} \\
\hline & $\begin{array}{l}\text { Before thermal } \\
\text { shock }\end{array}$ & $\begin{array}{l}\text { After thermal } \\
\text { shock }\end{array}$ & \\
\hline \multicolumn{4}{|c|}{$80 / 20 \%$ by weight FAF/OPC } \\
\hline No activator & 17 & 8.9 & 47 \\
\hline SMS & 19 & $9 \cdot 7$ & 49 \\
\hline SA & 17 & $9 \cdot 2$ & 43 \\
\hline SS & 20 & 11 & 46 \\
\hline \multicolumn{4}{|c|}{$90 / 10 \%$ by weight FAF/OPC } \\
\hline No activator & $8 \cdot 7$ & $4 \cdot 2$ & 51 \\
\hline SMS & $12 \cdot 0$ & $5 \cdot 9$ & 51 \\
\hline SA & 12 & $4 \cdot 7$ & 59 \\
\hline SS & 13 & $8 \cdot 8$ & 34 \\
\hline
\end{tabular}

compressive strength measurements were performed only on one sample.

In contrast, there were no visual cracks on the 90/10 ratio cement after heating at $600^{\circ} \mathrm{C}$. The strength of all samples fell after the thermal-shock tests. For the non-activated samples it declined by $46 \%$ and $52 \%$ for the $80 / 20$ and $90 / 10$ ratios, respectively. The decline in strength was similar for all activated $80 / 20$ ratio samples; it varied from 46 to $49 \%$. In the case of the 90/10 ratio blends, the SS-activated cement revealed the lowest reduction in strength of $34 \%$, whereas it was $51 \%$ and $60 \%$ for SMS and SA, respectively.

In summary, all activators improved the compressive strength of non-activated blends. The strength dropped for all the blends by more than $40-50 \%$ after five thermal shock cycles.

\section{Changes in crystalline phase composition after thermal} shock (XRD)

Figure 2 compares XRD data of non-heated 80/20 ratio FAF/ OPC samples against those of the samples exposed to five thermal shock cycles. Table 3 summarises the crystalline composition of $80 / 20$ ratio FAF/OPC blends.

After the $300^{\circ} \mathrm{C}$ hydration and before the thermal shock tests, all the patterns revealed the peaks of non-reacted FAF phases, such as quartz, mullite and haematite. In addition, the nonactivated blend had peaks of the OPC reaction product, tobermorite (characteristic peak at $7 \cdot 8^{\circ} 2 \theta$ ). There also was a wide peak between 12 and $14^{\circ} 2 \theta$ on this pattern, possibly from poorly crystallised $\mathrm{CSH}(\mathrm{I})$. The peaks for tobermorite also were present in the pattern of the SS-activated blend. The SIeve fitting program suggested the possible presence of riversideite (tobermorite 9A) in the SMS-activated sample. This phase generated a small peak that did not overlap with any other phase at $28 \cdot 2^{\circ} 2 \theta$. The formation of the OPC reaction products suggests a faster OPC than FAF hydration and hydrates crystallisation in the non-activated and SS-activated blends, which also was suggested by the calorimetric measurements. The SS-activated blend revealed an anhydrate peak $\left(2 \theta-25 \cdot 6^{\circ}\right)$ at both the FAF/OPC ratios. The intensity of this peak was $37 \%$ higher for the $90 / 10$ blend (data not shown) than for the 80/20 FAF/OPC blend. At the same time, calcite, identified in all other samples, was absent in the $90 / 10$ FAF/OPC SS-activated blend (main peak at $2 \theta-29 \cdot 5^{\circ}$ ), indicating a possible reaction between calcite originally present in the OPC with the SS activator and/or the reaction of calcium ions released during the cement hydration with the sulfate ions from the activator.

Although there were more crystalline products formed in the blend with SA activator, there was no tobermorite among them. Competition from carbonate anions for calcium cations could be a possible reason for this lack. The pattern of this sample showed the most intense calcite peaks. 


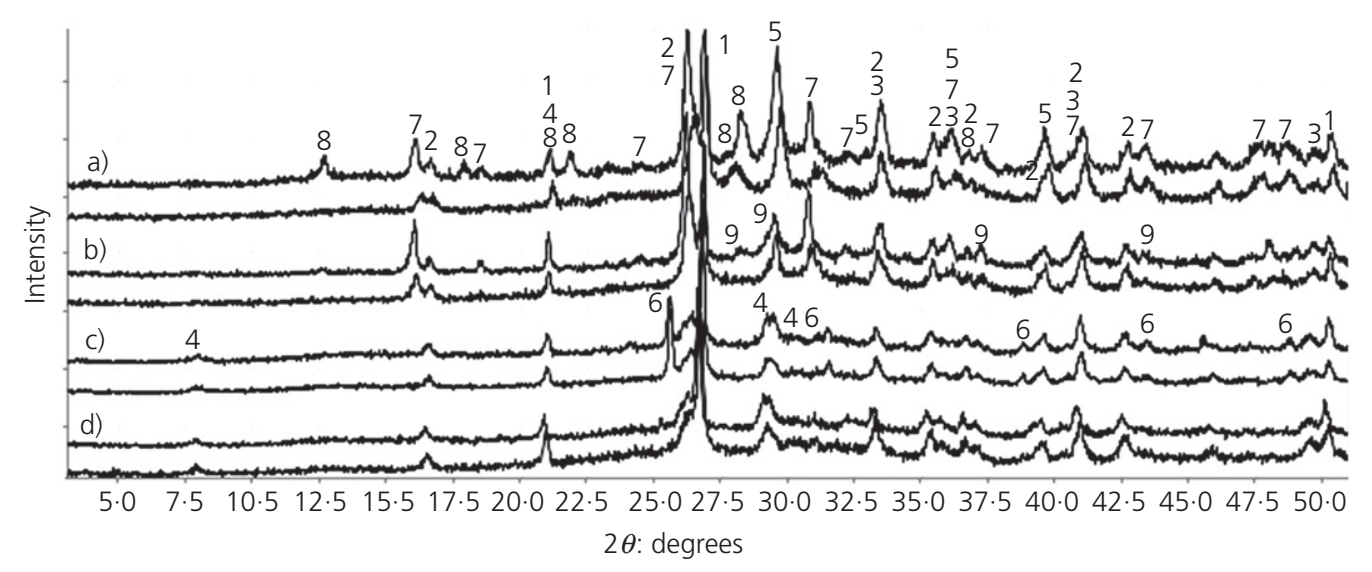

Figure 2. X-ray diffractograms for $80 / 20$ weight ratio FAF/OPC specimens before (top) and after (bottom) activated five thermal-shock cycles with (a) SA, (b) SMS, (c) SS and (d) non-activated; 1-quartz, 2-mullite, 3-haematite, 4-tobermorite, 5-calcite, 6-anhydrate, 7-analcime, 8-garronite, 9-riversideite
FAF hydrate analcime (aluminium sodium silicate hydrate) was identified in the XRD patterns of blends with SMS and SA activators. The presence of wairakite (sodium calcium aluminium silicate hydrate) cannot be excluded; however, its peaks overlap with those of analcime so its identification was problematic. SMS-activated blend patterns had weak peaks, whereas SA-activated blend ones had strong peaks of garronite (sodium calcium aluminium silicate hydrate). Garronite forms from the aluminium and silicon that mostly are supplied by FAF, sodium, which comes mostly from the activators, and calcium ions released during the OPC hydration. Intense garronite peaks in the patterns of the blend activated with SA support the concurrent hydration of OPC and FAF that was indicated by the merged high-intensity hydration heat peak in the calorimetric tests. The SMS, on the other hand, is a known accelerator of the cement hydration. Although it activates FAF, it is likely that OPC hydration happens faster, so accounting for the crystallisation of OPC hydration products. The co-existence of tobermorite and Ca-containing zeolites is interesting; zeolites are believed to form from the amorphous gel that precipitates as the initial hydration product of FAF dissolution (FernandezJimenez and Palomo, 2005). As an alternative to concurrent OPC and FAF hydration, it also is possible that garronite forms with calcium supplied by the OPC-hydration products that become unstable later under the experimental conditions. There were no portlandite peaks in any of the XRD patterns. Portlandite was shown to be unstable under conditions of thermal shock, decomposing with the formation of free lime and the re-crystallisation of portlandite when exposed to water, so damaging the matrix (Gill et al., 2012). Hence, the absence of portlandite in the OPC/FAF blends was a desirable feature.

The glassy amorphous halo between 18 and $35^{\circ} 2 \theta$ was present in all the hydrated samples. Both amorphous hydration products and glassy phases originally present in the fly ash contribute to this halo (Donatello et al., 2014). Since the same fly ash was used for all the blends and its lower reactivity in the case of SMS is unlikely, it is reasonable to conclude that the SMS-activated blend with the largest halo contained the largest amount of the amorphous hydration products, whereas the SA-activated blend with the smallest halo had the least, forming mostly crystalline hydrates. In all the cases, the halo slightly increased after the thermal shock, while the peak intensities of crystalline phases either decreased or disappeared.

Thus, the intensity of tobermorite peaks was reduced in non-activated- and SS-activated blends and had disappeared from the patterns of the SMS-activated one. The intensities of the analcime and garronite peaks significantly declined, suggesting their decomposition or transition to a poorly crystallised state. Finally, goethite and sillimanite possibly were present in the blend without activators; however, it was difficult to confirm this because of the overlapping patterns.

\section{Fourier transform infrared (FT-IR) study}

The spectrum for the original FAF (not shown) included four absorption bands: at 1035 and $776 \mathrm{~cm}^{-1}$ due to the $\mathrm{M}-\mathrm{O}$ (M: Si or Al) asymmetric $\left(\mathrm{V}_{\mathrm{as}} \mathrm{M}-\mathrm{O}\right)$ and symmetric $\left(\mathrm{V}_{\mathrm{s}} \mathrm{M}-\mathrm{O}\right)$ stretching vibrations, respectively, in $\mathrm{M}-\mathrm{O}-\mathrm{Si}$ linkages (Bakharev, 2005; Kline and Mullins, 1991; Uchino et al., 1991). The bands at 792 and $694 \mathrm{~cm}^{-1}$ were attributed, respectively, to Si-O symmetric stretching $\left(\mathrm{V}_{\mathrm{s}} \mathrm{Si}-\mathrm{O}\right)$ and Si-O bending $\left(\delta_{\mathrm{O}-\mathrm{Si}-\mathrm{O}}\right)$ vibrations in quartz (Ramasamy and Suresh, 2009; Saikia et al., 2008). Type II OPC revealed bands at $1621 \mathrm{~cm}^{-1}$ related to the $\mathrm{H}-\mathrm{O}-\mathrm{H}$ bending $\left(\delta_{\mathrm{H}-\mathrm{O}-\mathrm{H}}\right)$, at 1445 and $847 \mathrm{~cm}^{-1}$ associated with $\mathrm{C}-\mathrm{O}$ asymmetric stretching $\left(\mathrm{V}_{\mathrm{as}} \mathrm{C}-\mathrm{O}\right)$, and $\mathrm{O}-\mathrm{C}-\mathrm{O}$ bending $\left(\delta_{\mathrm{O}-\mathrm{C}-\mathrm{O}}\right)$ in carbonate $\mathrm{CO}_{3}{ }^{2-}$ (Gunasekaran et al., 2006; Xyla and Koutsoukos, 1989; Ylmen and Jaglid, 2013), whereas the bands at 1140 and $662 \mathrm{~cm}^{-1}$ belonged to the S-O symmetric stretching $\left(\mathrm{V}_{\mathrm{s}} \mathrm{S}-\mathrm{O}\right)$ and $\mathrm{O}-\mathrm{S}-\mathrm{O}$ bending 

the rest of the bands could be associated with calcium-silicate, -aluminate and -aluminoferrite anhydrous compounds (Ghosh and Handoo, 1980).

In comparison with the original FAF and OPC-spectra, after autoclaving the $\mathrm{FAF} / \mathrm{OPC}$ blends at $300^{\circ} \mathrm{C}$, the $\mathrm{V}_{\text {as }}$ M-O band shifted to a lower frequency, $1000-965 \mathrm{~cm}^{-1}$, from $1035 \mathrm{~cm}^{-1}$ while no significant changes was observed in the frequency of $\mathrm{V}_{\mathrm{s} \text { M-O }}$ band. As reported by many investigators (Criado et al., 2012; Fernandez-Jimenez and Palomo, 2005; García-Lodeiro et al., 2011; Mingyu et al., 2009; Palomo et al., 1999), such a shift could be interpreted as representing the formation of amorphous aluminosilicate hydrate gel with alkali-metal ions for charge compensation. It also is possible that calcium (Ca) liberated from hydrolysis of OPC in hydrothermal environments was part of the gel (N,C-A-S-H) assembled by the interactions between the calcium hydroxide $\left(\mathrm{Ca}(\mathrm{OH})_{2}\right)$ from OPC, and the aluminosilicate anhydrous compounds such as mullite $\left(3 \mathrm{Al}_{2} \mathrm{O}_{3}\right.$. $2 \mathrm{SiO}_{2}$ ) in $\mathrm{FAF}$ at $300^{\circ} \mathrm{C}$. The data also revealed that incorporating more OPC into FAF further shifted the $\mathrm{V}_{\text {as }}$ M-O band to a lower frequency from $1000 \mathrm{~cm}^{-1}$ for $90 / 10 \mathrm{FAF} / \mathrm{OPC}$ ratio to $965 \mathrm{~cm}^{-1}$ for $80 / 20$ ratio, seemingly suggesting that OPC promoted some changes in the molecular structure of $\mathrm{Na}_{2} \mathrm{O}-$ and $\mathrm{CaO}-\mathrm{Al}_{2} \mathrm{O}_{3}-\mathrm{SiO}_{2}-\mathrm{H}_{2} \mathrm{O}$ (N, C-A-S-H) gel. The other peaks present in these spectra were due to the water $\left(\delta_{\mathrm{H}-\mathrm{O}-\mathrm{H}}\right)$ at $1633 \mathrm{~cm}^{-1}, \mathrm{CO}_{3}{ }^{2-}\left(\mathrm{V}_{\text {as C-O }}\right.$ and $\left.\delta_{\mathrm{O}-\mathrm{C}-\mathrm{O}}\right)$ at 1446 and $876 \mathrm{~cm}^{-1}$, $\mathrm{SO}_{4}{ }^{2-}\left(\mathrm{V}_{\mathrm{s}} \mathrm{s}-\mathrm{O}\right)$ at $1167 \mathrm{~cm}^{-1}$, and quartz $\left(\mathrm{V}_{\mathrm{s} \text { Si-O }}\right.$ and $\left.\delta_{\mathrm{O}-\mathrm{Si}-\mathrm{O}}\right)$ at 798 and $695 \mathrm{~cm}^{-1}$. The similar shift of the $V_{\text {as M-O }}$ band to a lower frequency was detected from SMS-, SA- and SSactivated FAF/OPC cements after autoclaving, reflecting the formation of amorphous alkali metal-, calcium-aluminosilicate hydrate gel (N, C-A-S-H) gel. This shift to a lower frequency region between 991 and $973 \mathrm{~cm}^{-1}$ was more important at higher cement contents (80/20 FAF/OPC ratio). Additionally, there was no noticeable change in the frequency of the $\mathrm{V}_{\mathrm{s}} \mathrm{M}$-o band for both the 80/20 and 90/10 ratio FAF/OPC non-activated blends. The spectra with different alkali activators showed some specific features (Figure 3). Two prominent bands appeared at 1467 and $872 \mathrm{~cm}^{-1}$ with SA activator and were assigned to $V_{\text {as }}$ C-O and $\delta_{\text {O-C-O }}$ in carbonated compounds, while the quartz-associated bands were present at 797 and $694 \mathrm{~cm}^{-1}$. With SS, there were two $\mathrm{SO}_{4}{ }^{2-}$-related bands at 1165 and $673 \mathrm{~cm}^{-1}$, attributable respectively, to the $\mathrm{V}_{\mathrm{s}}$ s-o and $\delta_{\text {o-s-o }}$, possibly from calcium sulfate (Thompson and Palmer, 1988). In agreement with the XRD results, SS activator seemed to inhibit the carbonation reactions of cement; in fact, the carbonation-related bands at 1467 and $872 \mathrm{~cm}^{-1}$ were hardly visible. In contrast, the SMSactivated blend showed moderate carbonation. As expected, incorporating more OPC engendered the growth of carbonateassociated $V_{\text {as C-O }}$ and $\delta_{\text {O-C-o }}$ band peaks at 1458 and $874 \mathrm{~cm}^{-1}$ because of the carbonated compounds in the original OPC.

The spectra of non-activated and activated blends before and after the thermal shock closely resembled each other, 
suggesting that the hydrothermal reaction products (C-A-S-H and N,C-A-S-H gels, and carbonate- and sulfate-compounds), formed by $\mathrm{OPC}$ and the activators in cement bodies at $300^{\circ} \mathrm{C}$ survived the $600^{\circ} \mathrm{C}$ heat-cool water-quenching thermal-shock test, although decrease in their crystallinity was suggested by the XRD tests.

\section{Changes in differential thermal gravimetric analyses after the thermal shock}

Figure 4 presents the results of differential thermal gravimetric (DTG) analyses before and after the thermal shock for the $80 / 20$ weight ratio blends. Table 4 summarises the temperatures of the differential weight-loss peaks and the percentage mass lost in each temperature interval. The weight loss up to about $400^{\circ} \mathrm{C}$ can be associated with different hydrates (calcium, sodium) silica aluminate hydrates, including garronite (Foldvari, 2011), calcium aluminate and calcium silicate hydrates. Between about 400 and $600^{\circ} \mathrm{C}$, the dehydration of portlandite occurs along with the weight loss associated with the analcime (Harada et al., 1972); between 600 and $700^{\circ} \mathrm{C}$ there is decomposition related to carbonates. Thermogravimetric analysis (TGA) of the fly ash demonstrated some mass losses between about 700 and $800^{\circ} \mathrm{C}$. In the case of the thermal-shock-treated samples, the weight loss associated with carbonates shifted to lower temperatures and was analysed between 500 and $700^{\circ} \mathrm{C}$ (Table 4).

There is a general agreement between the DTG, FT-IR and XRD results. Before the thermal shock, the SMS-activated blend revealed the highest weight loss associated with different hydrates, $5 \cdot 07 \%$, and the non-activated cement the lowest, $3 \cdot 46 \%$, against $4.08 \%$ and $4.83 \%$ for the SS and SA activators, respectively. This is in agreement with the XRD results that showed the largest amorphous phase halo for the SMS-activated sample, suggesting a larger content of amorphous hydrates. Garronite likely contributed to the large dehydration peak of SA-activated blend at $\sim 67^{\circ} \mathrm{C}$ and the wide peak at $\sim 200^{\circ} \mathrm{C}$. None of the samples showed dehydration of portlandite, in agreement with the XRD patterns that were free of portlandite peaks. Analcime contributed to the weight loss between 400 and $600^{\circ} \mathrm{C}$; it was the largest loss for the SA-activated sample, in agreement with the most intense analcime XRD peaks. The SA-activated sample also had the most important carbonate-decomposition weight loss, $3 \cdot 65 \%$ compared with $1 \cdot 84 \%$ and $1 \cdot 01 \%$ for the SMS- and SS-activated blends, respectively, once more supporting findings from the XRD measurements.
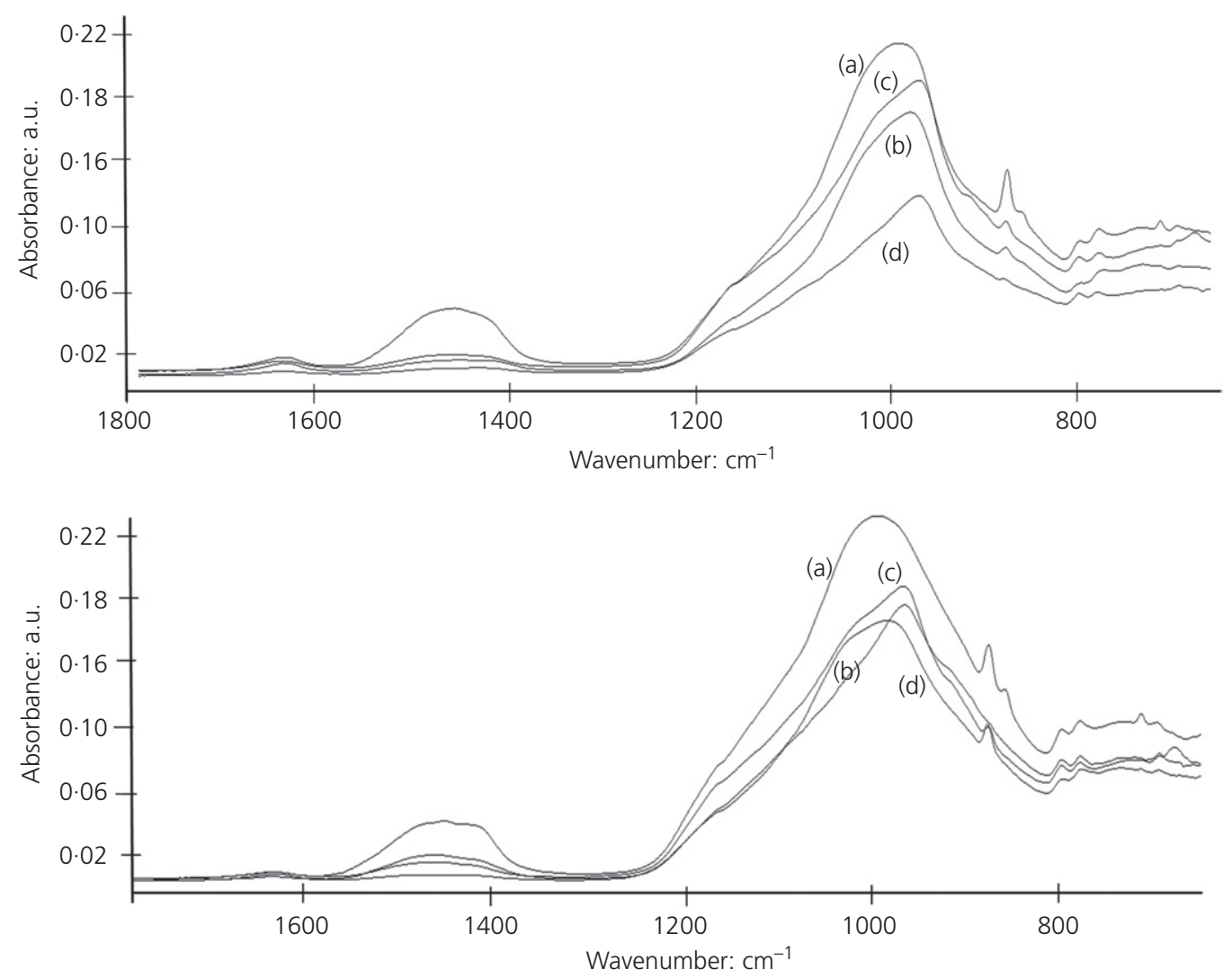

Figure 3. Fourier transform infrared spectra of $80 / 20$ weight ratio FAF/OPC blend before (top) and after five thermal-shock cycles (bottom) activated with (a) SA, (b) SMS, (c) SS and (d) non-activated 

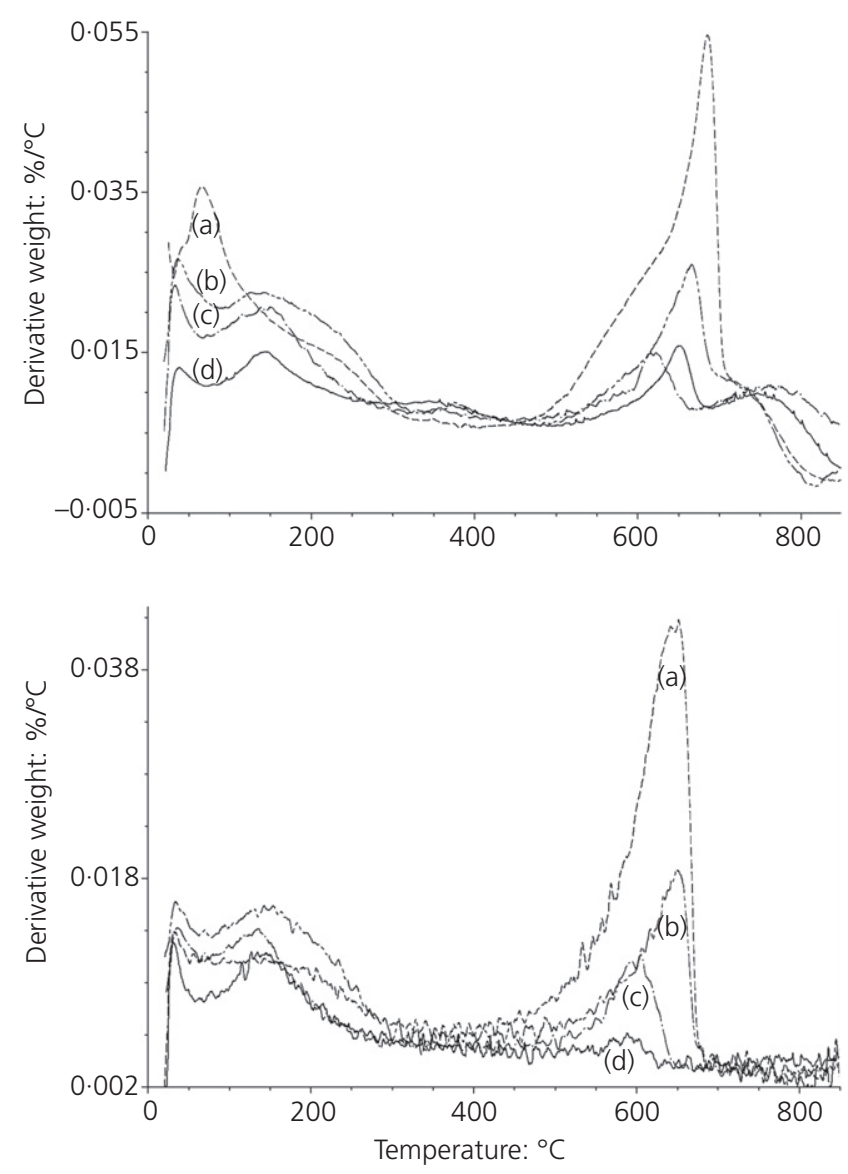

Figure 4. Differential thermal gravimetric analyses (DTG) of 80/20 weight ratio FAF/OPC blend before (top) and after (bottom) five thermal-shock cycles activated with (a) SA (b) SMS (c) SS and (d) non-activated

After the thermal shock, there were three major changes in the DTG results. The amounts of thermally decomposing phases declined in all three temperature ranges, suggesting fewer water-containing hydrates, analcime and carbonates. The decomposition temperature of carbonates dropped (the start of the decomposition shifted from about 600 to about $550^{\circ} \mathrm{C}$ ) possibly due to a decrease in their crystallinity. Finally, the broad decomposition peak between about 700 and $800^{\circ} \mathrm{C}$ attributed to the non-reacted FAF disappeared. The lower amounts of hydrates, analcime and carbonates after the thermal-shock tests also agree with the results of the XRD analysis.

\section{Changes in microstructure and elemental composition after thermal shock (SEM/EDX)}

Figure 5 shows the micrographs of the FAF/OPC samples alone and with different activators before and after the thermal shock. All the samples contained fly ash cenospheres covered with hydration products and surrounded by irregular, mostly amorphous nodules. Among the three activators, soda ash produced samples with the highest surface roughness. There was no dramatic difference in samples' morphologies after the thermal shock, which, for the most part, remained amorphous.

Elemental analysis showed sites with the composition typical of the $\mathrm{CSH}$ gel, tobermorite, garranite, calcium carbonate, riversideite along with quartz, and stand-alone large anhydrate crystals, supporting the XRD findings (Figure 5). The point 10 denotes the site with the typical composition of wairakite that could not be identified by XRD owing to its pattern strongly overlapping with that of analcime. In contrast, crystals of analcime expected from the XRD analysis were not found.

\section{Conclusions}

Performance of very high-content FAF blends with OPC non-activated or activated with sodium meta silicate, sodium sulfate and soda ash, hydrated at $300^{\circ} \mathrm{C}$ and subjected to high thermal shock (five cycles of $600^{\circ} \mathrm{C}$ heat followed by $25^{\circ} \mathrm{C}$ water cooling) was evaluated. The following general conclusions can be drawn from the study.

(a) The major product of the blend hydration for $24 \mathrm{~h}$ at $85^{\circ} \mathrm{C}$ followed by $24 \mathrm{~h}$ at $300^{\circ} \mathrm{C}$ is calcium,

\begin{tabular}{|c|c|c|c|c|c|c|}
\hline \multirow[b]{2}{*}{ Activator } & \multicolumn{3}{|c|}{ Before the thermal shock } & \multicolumn{3}{|c|}{ After the thermal shock } \\
\hline & $70-400^{\circ} \mathrm{C}$ & $400-600^{\circ} \mathrm{C}$ & $600-700^{\circ} \mathrm{C}$ & $70-400^{\circ} \mathrm{C}$ & $400-500^{\circ} \mathrm{C}$ & $500-700^{\circ} \mathrm{C}$ \\
\hline \multicolumn{7}{|c|}{ 80/20 FAF/OPC } \\
\hline None & $3 \cdot 46$ & $1 \cdot 33$ & 1.08 & $1 \cdot 70$ & $0 \cdot 13$ & $0 \cdot 24$ \\
\hline SMS & $5 \cdot 07$ & $1 \cdot 61$ & $1 \cdot 84$ & $2 \cdot 79$ & 0.33 & $1 \cdot 60$ \\
\hline SS & $4 \cdot 08$ & $1 \cdot 51$ & $1 \cdot 01$ & 1.90 & 0.25 & $0 \cdot 78$ \\
\hline SA & $4 \cdot 83$ & $2 \cdot 22$ & $3 \cdot 65$ & $2 \cdot 29$ & 0.46 & $3 \cdot 79$ \\
\hline
\end{tabular}

Table 4. Thermal decomposition temperature ranges and associated weight losses of specimens before and after five thermal-shock cycles 

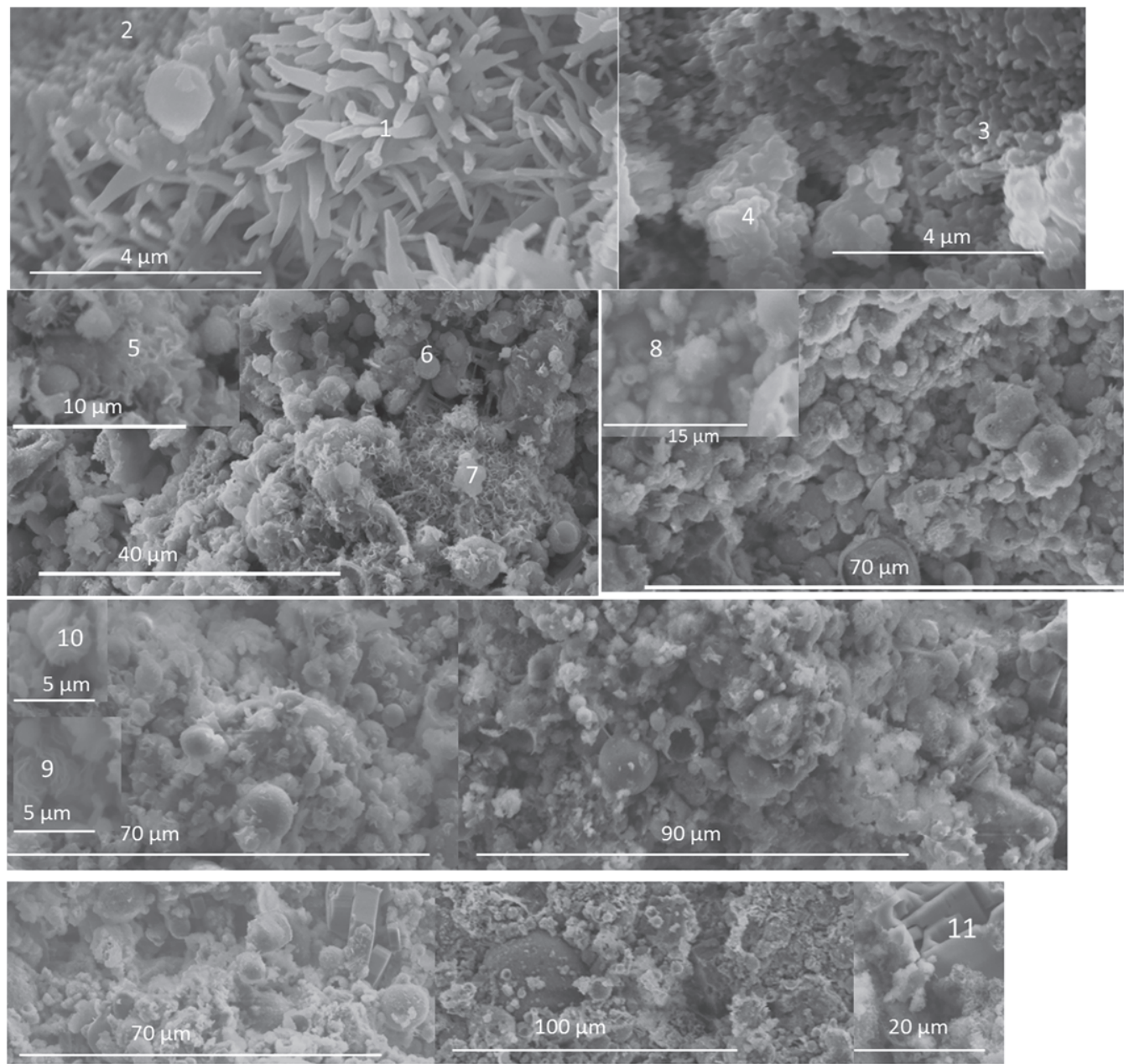

\begin{tabular}{lcccccccc}
\hline Sample & Point & $\mathrm{Al}$ & $\mathrm{Ca}$ & $\mathrm{K}$ & $\mathrm{Na}$ & $\mathrm{Si}$ & $\mathrm{S}$ & Possible phase \\
\hline 80/20-before TS & 1 & $3 \cdot 8$ & 19 & $1 \cdot 8$ & - & 15 & - & CSH \\
& 2 & $4 \cdot 2$ & 15 & $1 \cdot 6$ & - & 18 & - & Tobermorite \\
\hline 80/20-after TS & & $2 \cdot 1$ & 12 & $1 \cdot 1$ & $0 \cdot 1$ & 11 & - & CSH \\
& 4 & $2 \cdot 3$ & $4 \cdot 8$ & $0 \cdot 6$ & $0 \cdot 4$ & $8 \cdot 9$ & $0 \cdot 6$ & - \\
\hline 90/10-SA-before TS & 5 & $5 \cdot 1$ & 16 & $0 \cdot 9$ & $2 \cdot 5$ & 16 & - & CSH (precursor) \\
& 6 & $9 \cdot 5$ & $4 \cdot 5$ & $1 \cdot 7$ & $1 \cdot 2$ & 19 & - & Garronite \\
& 7 & 11 & $5 \cdot 1$ & - & $2 \cdot 6$ & 20 & - & Garronite \\
\hline 90/10-SA-after TS & 8 & $6 \cdot 4$ & $2 \cdot 7$ & $1 \cdot 0$ & $1 \cdot 0$ & 12 & - & Garronite \\
\hline 90/10-SMS-before & 9 & $5 \cdot 5$ & 12 & $3 \cdot 3$ & $0 \cdot 8$ & 15 & - & Riversideite (precursor) \\
TS & 10 & 10 & 3 & 1 & 2 & 19 & - & Wairakite (precursor) \\
\hline 80/20-SS-after TS & 11 & $0 \cdot 1$ & 12 & - & - & $0 \cdot 2$ & 13 & Anhydrate \\
\hline
\end{tabular}

Figure 5. Scanning electron micrographs of typical cement microstructures and their elemental compositions for 80/20 and 90/10 weight ratios FAF/OPC blends

sodium-aluminosilicate hydrate $(\mathrm{C}, \mathrm{N}-\mathrm{A}-\mathrm{S}-\mathrm{H})$ gel. More of it forms in activated FAF/OPC blends than in the non-activated one, leading to their high compression strength. SMS and SA activators significantly accelerate the hydration of both FAF and OPC. The SA activator promotes the products' crystallisation, whereas the hydration products of the SMS-activated blend for the most part stay amorphous at early hydration times. SS has the weakest accelerating effect on FAF, likely resulting in delayed FAF hydration in comparison with the OPC.

(b) The OPC hydration products, such as small amounts of tobermorite and possibly CSH gel, crystallise in the 
non-activated blends and in the presence of the SS activator, where OPC hydration starts before pozzalan reactions of FAF. The hydrates of sodium calcium aluminium silicate, such as garronite (SA activator) or wairakite (SMS), along with the FAF-hydration product, analcime, form when OPC and FAF hydrate simultaneously in SA- and SMS-activated blends. Portlandite was not detected in any of the samples. This can be explained by its partial carbonation in the blends with SMS and SA, anhydrate formation in the blend with SS activator, and reactions with FAF with the formation of calcium-containing hydrates.

(c) The thermal shock tests reduced the amount of thermally decomposable hydrates and the peak intensities of crystalline products such as garronite and analcime, while tobermorite in non-activated blends survived the tests. In general, the crystallinity of the samples decreased after the thermal shock tests. Although all activators improved the initial compressive strength of the nonactivated sample, the compressive strength decreased more than $40 \%$ and more than $50 \%$, respectively, for $80 /$ 20 and 90/10 weight ratio blends after the five thermalshock cycles for both activated and non-activated blends.

\section{Acknowledgements}

This publication was based on the work supported by the Geothermal Technologies Office in the US Department of Energy (DOE) Office of Energy Efficiency and Renewable Energy (EERE), under the auspices of the US DOE, Washington, DC, under Contract No. DE-AC02-98CH 10886 -98CH10886. Research was carried out in part at the Center for Functional Nanomaterials, Brookhaven National Laboratory, which is supported by the US Department of Energy, Office of Basic Energy Sciences, under Contract No. DE-SC0012704.

\section{REFERENCES}

Andini S, Cioffi R, Colangelo F, Grieco T, Montagnaro F and Santoro L (2008) Coal fly ash raw material for the manufacture of geopolymer-based products. Waste Management 28(2): 416-423.

Bakharev T (2005) Resistance of geopolymer materials to acid attack. Cement and Concrete Research 35(4): 658-670.

Bakharev T (2006) Thermal behavior of geopolymers prepared using class F fly ash and elevated temperature curing. Cement and Concrete Research 36(6): 1134-1147.

Ben Haha M, De Weerdt K and Lothenbach B (2010) Quantification of the degree of reaction of fly ash. Cement and Concrete Research 40(11): 1620-1629.

Bentz DP and Ferraris CF (2010) Rheology and setting of high volume fly ash mixtures. Cement and Concrete Research 32(4): 265-270.

Berry EE, Hemmings RT and Cornelius BJ (1990) Mechanism of hydration reactions in high volume fly ash pastes and mortars. Cement and Concrete Composites 12(4): 253-261.
Bignozzi MC, Manzi S, Natali ME, Rickard WDA and van Riessen A (2014) Room temperature alkali activation of fly ash: The effect of $\mathrm{Na}_{2} \mathrm{O} / \mathrm{SiO}_{2}$ ratio. Construction and Building Materials 69: 262-270.

Chi M and Huang R (2013) Binding mechanism and properties of alkali-activated fly ash/slag mortars. Construction and Building Materials 40: 291-298.

Criado M, Fernández Jiménez A, Sobrados I, Palomo A and Sanz $J$ (2012) Effect of relative humidity on the reaction products of alkali activated fly ash. Journal of the European Ceramic Society 32(11): 2799-2807.

Davidovits J (1991) Geopolymers: Inorganic polymeric new materials. Journal of Thermal Analysis 37(8): 1633-1656.

Deschner F, Winnefeld F, Lothenbach B et al. (2012) Hydration of Portland cement with high replacement by siliceous fly ash. Cement and Concrete Research 42(10): 1389-1400.

Donatello S, Fernandez-Jimenez A and Palomo A (2013a) Very high volume fly ash cements. Early age hydration study using $\mathrm{Na}_{2} \mathrm{SO}_{4}$ as an activator. Journal of American Ceramic Society 96(3): 900-906.

Donatello $S$ et al. (2013b) Durability of very high volume fly ash cement pastes and mortars in aggressive solution. Cement and Concrete Composites 38: 12-20.

Donatello S, Kuenzel C, Palomo A and Fernandez-Jimenez A (2014) High temperature resistance of a very high volume fly ash cement. Cement and Concrete Composites 45: 234-242.

Duran-Herrera A, Juarez CA, Valdez P and Bentz DP (2011) Evaluation of sustainable high volume fly ash concretes. Cement and Concrete Composites 33(1): 39-45.

Feldman RF, Carette GG and Malhotra VM (1990) Studies on mechanics of development of physical and mechanical properties of high-volume fly ash-cement pastes. Cement and Concrete Composites 12(4): 235-251.

Fernandez-Jimenez A and Palomo A (2005) Composition and microstructure of alkali activated fly ash binder: Effect of the activator. Cement and Concrete Research 35(10): 1984-1992.

Foldvari M (2011) Handbook of Thermogravimetric System of Minerals and its Use in Geological Practice. Geological Institute of Hungary, Budapest, Hungary, Occasional Papers, vol. 213.

Fraay ALA, Bijen JM and de Haan YM (1989) The reaction of fly ash in concrete a critical examination. Cement and Concrete Research 19(2): 235-246.

García-Lodeiro I, Palomo A, Fernández-Jimenez A and Macphee DE (2011) Compatibility studies between N-A-S-H and $\mathrm{C}-\mathrm{A}-\mathrm{S}-\mathrm{H}$ gels. Study in the ternary diagram $\mathrm{Na}_{2} \mathrm{O}-\mathrm{CaO}-\mathrm{Al}_{2} \mathrm{O}_{3}-\mathrm{SiO}_{2}-\mathrm{H}_{2} \mathrm{O}$. Cement and Concrete Research 41(9): 923-931.

Ghosh SN and Handoo SK (1980) Infrared and Raman spectral studies. Cement and Concrete Research 10(6): 771-782.

Gill SK, Pyatina T and Sugama T (2012) Thermal shock-resistant cement. Geothermal Resources Council Transactions 36: 445-451. 
Gunasekaran S, Anbalagan G and Pandi S (2006) Raman and infrared spectra of carbonate of calcite structure. Journal of Raman Spectroscopy 37(9): 892-899.

Gurney L, Bentz DP, Sato T and Weiss WJ (2012) Reducing set retardation in high volume fly ash mixtures with the use of limestone: Improving constructability of sustainability. Transportation Research Record, Journal of the Transportation Research Board, 2290, 139-146.

Harada K, Tanaka K and Nagashima K (1972) New data on the analcime-wairakite series. American Mineralogist 57(5-6): 924-931.

Joshi SV and Kadu MS (2012) Role of alkali activator in development of eco-friendly fly ash based geopolymer concrete. International Journal of Environmental Science and Development 3: 417-421.

Kline AA and Mullins ME (1991) Sol-gel kinetics followed by cylindrical attenuated total reflectance infrared spectroscopy. Journal of the American Ceramic Society 74(10): 2559-25563.

Komnitsas K and Zaharaki D (2007) Geopolymerization: A review and prospects for the minerals industry. Minerals Engineering 20(14): 1261-1277.

Lam L, Wong YL and Poon CS (2000) Degree of hydration and gel/space ratio of high-volume fly ash/cement systems. Cement and Concrete Research 30(5): 747-756.

Lohani TK, Jena S, Dash KP and Padhy M (2012) An experimental approach on geopolymer recycled concrete using partial replacement of industrial byproduct. International Journal of Civil and Structural Engineering 3: 141-149.

Mandal S and Majumdar D (2009) Study on the alkali activated fly ash mortar. The Open Civil Engineering Journal 3: 98-101.

Mingyu H, Xiaomin Z and Fumei L (2009) Alkali-activated fly ash-based geopolymer with zeolite or bentonite as additives. Cement and Concrete Composites 31(10): $762-768$.

Pacewska B and Wilinska I (2013) Hydration of cement composites containing large amount of waste materials. Procedia Engineering 57: 53-62.
Palomo A, Grutzeck MW and Blanco MT (1999) Alkali-activated fly ashes A cement for the future. Cement and Concrete Research 29(8): 1323-1329.

Ramasamy V and Suresh G (2009) Mineral characterization and crystalline nature of quartz in Ponnaiyar river sediments, Tamilnadu, India. American-Eurasian Journal of Science Research 4(2): 103-107.

Rodriguez ED, Bernal SA, Provis JL, Paya J, Monzo JM and Borrachero MV (2013) Effect of nano silica-based activators on the performance of an alkali-activated fly ash binder. Cement and Concrete Composites 35(1): 1-11.

Saikia BJ, Parthasarathy G and Sarmah NC (2008) Fourier transform infrared spectroscopic estimation of crystallinity in $\mathrm{SiO}_{2}$ based rocks. Bulletin of Material Science 31(5): 775-779.

Shi C and Day RL (1995) Acceleration of the reactivity of fly ash by chemical activation. Cement and Concrete Research 25(1): 15-21.

Thompson MM and Palmer RA (1988) In situ Fourier transform infrared diffuse reflectance and photoacoustic spectroscopy characterization of sulfur-oxygen species resulting from the reaction of $\mathrm{SO}_{2}$ with $\mathrm{CaCO}_{3}$. Applied Spectroscopy 42(6): 945-951.

Uchino T, Sakka T and Iwasaki M (1991) Interpretation of hydrated states of sodium silicate glasses by infrared and Raman analysis. Journal of American Ceramic Society 74(2): 306-313.

van Jaarsveld JGS, van Deventer JSJ and Lukey GC (2002) The effect of composition and temperature on the properties of fly ash- and kaolinite-based geopolymers. Chemical Engineering Journal 89(1-3): 63-73.

Xyla AG and Koutsoukos PG (1989) Quantitative analysis of calcium carbonate polymorphs by infrared spectroscopy. Journal of Chemical Society, Faraday Transactions 1 85(10): 3165-3172.

Ylmen R and Jaglid U (2013) Carbonation of Portland cement studied by diffuse reflection Fourier transform infrared spectroscopy. International Journal of Concrete Structures and Materials 7(2): 119-125.

\section{WHAT DO YOU THINK?}

To discuss this paper, please submit up to 500 words to the editor at journals@ice.org.uk. Your contribution will be forwarded to the author(s) for a reply and, if considered appropriate by the editorial panel, will be published as a discussion in a future issue of the journal. 